\title{
La Banda de Arriba (Cafayate, Salta). Acciones de comunicación estratégica para vincular a los arqueólogos con los públicos objetivos
}

\author{
Rossana Ledesma" y Néstor Cruz"
}

Recibido:

15 de marzo de 2017

Aceptado:

18 de agosto de 2017

\section{Resumen}

En este trabajo presentamos las acciones de extensión y divulgación de la producción científica de las investigaciones arqueológicas realizadas en el paraje La Banda de Arriba (Cafayate, Salta). Por medio de un proyecto de extensión efectuamos el montaje de una muestra temporaria, caracterizada por el trabajo conjunto de arqueólogos, comunicadores sociales y la localidad de Cafayate. Consideramos que los públicos objetivos serán los encargados de definir los parámetros del proyecto en un escenario complejo y dinámico, lleno de experiencias colectivas e individuales que fueron demarcando diferentes momentos, susceptibles de ser analizados desde una perspectiva interdisciplinaria. El objetivo general de este trabajo es mostrar las primeras experiencias interdisciplinarias del proyecto Cafayate para gestar acciones de comunicación que le permitan vincularse con los públicos objetivos.

\section{La Banda de Arriba (Cafayate, Salta). Strategic communication actions linking archaeologists to target audiences}

\begin{abstract}
In this article, we present the outreach and science popularization actions of the archaeological research undertaken at La Banda de Arriba (Cafayate, Salta). This outreach program set-up a temporary exhibition which was characterized by the collaborative work of archaeologists, social interlocutors and the community. We saw the target audience as responsible for defining the projects parameters within a complex and dynamic scenario. A scenario full of collective and individual experiences that served to demarcate different moments, these could then be analyzed from an interdisciplinary perspective. The general objective of this article was then, to present the Cafayate Project's first interdisciplinary experiences, experiences which generated communication between them and the target groups.
\end{abstract}

\section{Palabras clave}

Planificación estratégica Comunicación

Exposición arqueológica Extensión

Divulgación científica

\section{Keywords}

Strategic planning Communication Archaeological exhibition Outreach

Science popularization 


\section{Introducción}

El objetivo general de este trabajo es presentar una de las acciones de comunicación estratégica diseñadas para vincular el equipo de arqueólogos de la Universidad Nacional de Salta (UNSa) con la localidad de Cafayate (Salta), en particular con los integrantes del paraje La Banda de Arriba. La primera de ellas fue el diseño y montaje de una muestra arqueológica temporal denominada "Cafayate hace mil años" que fue realizada por medio de un proyecto de extensión universitaria de la UNSa (convocatoria año 2014).

El equipo del proyecto arqueológico Cafayate está conformado por arqueólogos y estudiantes de la carrera de Antropología de la Universidad de Salta y si bien el grupo trabaja desde el año 1997, recientemente se produjeron recambios generacionales que motivaron la discusión interna sobre las líneas de trabajo a desarrollar en el futuro. Ante la cantidad de interrogantes se trató en profundidad la divulgación de los resultados, el compromiso social, la gestión de permisos ante las autoridades de aplicación y la consulta con los pueblos originarios. En este contexto se incorporaron investigadores y estudiantes de la carrera de Ciencias de la Comunicación de la misma universidad.

En esta ocasión no se discutirá sobre el compromiso social de la profesión, pero no es desconocido que los pueblos originarios están reclamando su participación en la gestión de permisos de investigación como el Protocolo de consulta previa, libre e informada a Pueblos Originarios en Argentina. Consulta que también es requerida informalmente por vecinos de la localidad de Cafayate. En este momento del análisis se puede decir que la investigación científica necesita ser legitimada por la localidad, en términos de Prats (1997), mediante las acciones de extensión y divulgación.

Si bien se habían realizado diversas acciones como cursos, charlas, talleres y publicaciones sobre el pasado prehispánico y conservación del patrimonio destinados a la localidad en general y a públicos objetivos (artesanos, guías de turismo, docentes), ha sido permanente la interpelación por parte de los asistentes hacia los arqueólogos sobre el destino de los objetos arqueológicos obtenidos en rescates y excavaciones, especialmente los provenientes del paraje La Banda de Arriba (Ledesma, 2014). Con las reflexiones e inquietudes mencionadas se elaboró el proyecto de extensión universitaria "Muestra Arqueológica Cafayate hace mil años" con los objetivos de relatar la historia desde la localidad con el aporte de la Arqueología, montar una exposición temporaria con los objetos arqueológicos obtenidos en excavaciones que se encuentran en el Museo de Antropología de Salta y sentar las bases para la realización de un museo arqueológico local de gestión pública.

Tradicionalmente, las investigaciones arqueológicas han formado parte de lo que se denomina investigación básica pero en la última década se han incrementado las acciones de los arqueólogos en proyectos de divulgación de la producción científica y de extensión universitaria. Estos proyectos se han planteado el objetivo de llevar adelante actividades que hagan accesible el conocimiento científico tecnológico al público en general y/o profundizar la vinculación de las Universidades Públicas e Institutos Universitarios Nacionales con la comunidad en que se insertan a través de propuestas orientadas a mejorar la calidad de vida de su población. Son diversos los programas que avalan la divulgación y la extensión como los Proyectos de Divulgación Científico-Tecnológica (CONICET), Voluntariado Universitario (Secretaría de Políticas Universitarias) y Extensión Universitaria (Secretaría de Políticas Universitarias y Universidades Nacionales). Aunque son discutibles los términos e implicancias de las actividades de divulgación, extensión y voluntariado, es indudable el incremento de proyectos arqueológicos en los mencionados programas dentro de las líneas de turismo y conservación del patrimonio (Brunas, Ledesma y Rivas, 2012). Aunque se ha generalizado el concepto de transferencia, actualmente éste se encuentra restringido al proceso por el que se transfiere un producto, principalmente tecnología, procedimientos 
y métodos de fabricación desde instituciones de investigación estatal a otras instituciones públicas o privadas con una contraprestación económica y mecanismos de propiedad intelectual como patentes de invención y modelos de utilidad (CONICET, Dirección de Vinculación tecnológica, red de vinculadores, 2016). En el caso específico de la "Muestra Arqueológica Cafayate hace mil años", se trata de acciones de divulgación de la producción científica y de extensión universitaria.

La definición de comunidad donde se insertan las investigaciones es amplia y debió ser precisada tanto en su alcance antropológico como comunicacional. El concepto de localidad empleado por Prats (2005) resulta apropiado en este caso y es aplicado a la delimitación territorial y administrativa del municipio de Cafayate. Este se encuentra habitado por una comunidad personalmente interrelacionada, sin un grado de anonimato significativo, con un mundo conocido y de conocidos (Prats, 2005). Para el desarrollo de este trabajo se definieron dos niveles: el primero abarca la localidad de Cafayate, conformada administrativamente por el municipio y el segundo comprende el paraje La Banda de Arriba, el cual está incluido territorialmente en el primero y del cual depende administrativamente. Dicho paraje presenta un alto grado de auto pertenencia local y campesina, aunque sin referencias explícitas de identificación con los pueblos originarios o con la comunidad diaguita-calchaquí.

Desde la mirada comunicacional y según Bongiovanni (2011), los públicos objetivos son un agregado de personas que están unidas por un mismo interés en relación con la organización (en este caso el equipo del Proyecto Cafayate). Es decir, los grupos están unidos mentalmente con la organización y no necesariamente comparten un espacio geográfico, son definidos por la organización al identificar roles y status de sus públicos. Esta definición es más abarcadora y compleja que la de público receptor y se propone dado que las estrategias de comunicación deben realizarse con una adecuada identificación de los públicos. Los habitantes de La Banda de Arriba fueron definidos como el primer grupo de público objetivo, ya que la muestra se basa inicialmente en los hallazgos realizados allí pero no puede desprenderse de la localidad de Cafayate donde se encuentra inserta territorial y administrativamente. La dinámica de estos públicos objetivos se observa en la circulación permanente de los vecinos del paraje en la localidad y viceversa, por razones laborales, educativas, sanitarias, recreativas y de abastecimiento.

\section{Antecedentes}

El proyecto Carta Arqueológica del Departamento Cafayate (Salta) es la continuación de las investigaciones arqueológicas realizadas en el municipio de Cafayate desde el año 1997. En los primeros proyectos los objetivos estaban orientados a estudiar las ocupaciones del período Formativo en la zona. Ante la heterogeneidad del registro $\mathrm{y}$ al observarse reocupaciones en el espacio, fue necesario integrar las evidencias en estudios territoriales. Esto ha permitido contar con una base de datos de cuarenta sitios arqueológicos ubicados cronológicamente desde el período Formativo hasta momentos del contacto Hispano Indígena. Específicamente, en el paraje La Banda de Arriba se han registrado siete sitios arqueológicos, efectuándose rescates en tres de ellos. En todos los casos se trata de inhumaciones colectivas con acompañamiento funerario, ubicadas cronológicamente en los períodos Formativo Superior y Desarrollos Regionales (Ledesma, 2010a, 2010b; Ledesma y Subelza, 2009, 2014; Subelza, 2008). En el año 2000 se realizó una muestra con los resultados de las primeras excavaciones organizadas por el Museo de Antropología de Salta y la UNSa ${ }^{1}$. Incluso se había dejado una pequeña exposición de cartelería en el centro vecinal de La Banda de Arriba. Ante el pedido expreso de realizar una nueva exposición, resultaba necesario proponer una metodología de trabajo superadora para poder desarrollar acciones de extensión y divulgación científica
1. Esta exposición fue realizada en la Municipalidad de Cafayate (Lo Celso, Lescano y Barbarán, 2000). 
2. Proyecto "El Legado de los pueblos originarios”, Secretaría de Extensión Universitaria, UNSa.
En los cursos de extensión realizados en el año $2013^{2}$, los asistentes expresaron su inquietud sobre el destino de los objetos arqueológicos obtenidos en las excavaciones. Las piezas arqueológicas se encuentran en custodia del Museo de Antropología de Salta ya que el departamento Cafayate no cuenta con un museo de gestión pública que garantice su resguardo. La propuesta de realizar una exposición temporaria surgió desde los integrantes del proyecto ante la inquietud de los asistentes, la cual fue presentada ante las autoridades municipales, provinciales y la UNSa. Desde el inicio, los integrantes del equipo Cafayate consideraron fundamental realizar una exposición en la que los arqueólogos se desplacen del protagonismo en la confección del guion museográfico.

Realizar una exposición con la mirada local implicaba desplazarse desde un relato científico hacia una historia que muestre a los protagonistas, a los vecinos de un sitio arqueológico. Se siguió inicialmente el planteo propuesto por la nueva museología de Marc Maure (1995) y en esta línea se proyectó la muestra de tal forma que conjugara la función de mostrar los objetos culturales al tiempo que hiciera visible a localidad.

Tradicionalmente se considera a la exposición museográfica como el resultado de un proceso de selección y manipulación de la información emitida por los arqueólogos a partir de las piezas arqueológicas. En este caso se propuso montar una exposición emotiva y didáctica a la vez, donde las preguntas y relatos de los integrantes de La Banda de Arriba fueran incorporados e integrados en el relato de la muestra. El diseño de la exposición fue previsto como un espacio de negociación entre la organización (proyecto Cafayate), la localidad de Cafayate, el paraje de La Banda de Arriba, instituciones municipales y provinciales.

En el proyecto original de extensión, el equipo planificó las siguientes actividades: elaboración del documento del plan director, realización de entrevistas a informantes claves y actores sociales, diseño de la muestra expositiva, plan comunicacional, programación de la inauguración, montaje y desmontaje de la muestra. El cronograma pudo realizarse en forma lineal y cronológica con las actividades mencionadas, especialmente con el diseño de la muestra expositiva, las entrevistas y el plan comunicacional que se presentan a continuación. El trabajo interdisciplinario fue realizado en conjunto entre comunicadores y arqueólogos (docentes y estudiantes), con consensos y acuerdos permanentes, replanteos y búsquedas de alternativas ante los imprevistos. En esta instancia se pudo hacer evidente que el objetivo de elaborar una muestra participativa con la localidad necesitaba fundamentalmente de flexibilidad profesional para modificar el plan director y las propias formaciones teóricas y metodológicas. Las acciones fueron transversales, con objetivos específicos, con permanentes ajustes en su ejecución y con el período de exposición como la única actividad inamovible.

\section{Plan comunicacional}

El plan de comunicación tenía como objetivos específicos lograr que la localidad participe en la planificación de la muestra y se apropie simbólicamente de los estudios realizados en su territorio y de los bienes arqueológicos, promover la legitimación del trabajo del equipo de investigación en Cafayate y buscar coherencia necesaria entre el discurso desarrollado, los soportes de comunicación utilizados y los intereses de cada público.

Se entiende que la planificación es una forma de organización para la acción (Onocko Campos, 2007) que debe estar situada en un contexto histórico, debido a que no existe un método general capaz de dar cuenta de las interrelaciones entre propósito, método y organización en las situaciones o momentos históricos. Desde esta mirada se propone 
a la planificación como un dispositivo capaz de desplegar un momento de experiencia conjunta entre planificados y planificadores, superando la instancia instrumental con la que fue concebida la planificación normativa (Abatedaga, 2008).

El plan de comunicación que se realizó se basa en líneas generales en la perspectiva teórica de las teorías de la recepción y de los estudios culturales de la comunicación en América Latina. La matriz teórica general fue la teoría "martinbarberiana" de las mediaciones, porque permite relacionar lo popular con lo industrial-comercial y lo cultural con las producciones mediáticas vigentes (Bonilla, Cataño, Rincón y Zuluaga, 2012). Desde esta perspectiva el concepto de mediación no significa que los medios median sino que los medios entran en relación: medios y sociedad, medios y vidas cotidianas, medios y movimientos sociales, medios y estructuras de producción (Martin Barbero, 1987). Se genera de esta forma una relación multidimensional y compleja entre los diferentes actores sociales que se reconocen al momento de comunicar.

Se propuso a la teoría de las mediaciones como eje vertebrador del proyecto porque presenta una mirada desde la cual se puede pensar la acción comunicacional desde los públicos objetivos y desde sus opiniones, las que le dan contenido a la planificación. En el caso de la muestra arqueológica "Cafayate hace mil años" las mediaciones son identificadas a partir de las activaciones constantes de los participantes en la red diseñada para tal fin, que a su vez conforman un proceso comunicacional aparentemente entrópico pero guiado estratégicamente por un plan de comunicación que intentó instalar conversaciones en todo momento (Cruz, 2016). Las aproximaciones a esas decisiones estratégicas fueron indagar sobre el lugar de realización, los destinatarios, los interrogantes y los contenidos de la muestra, los objetos arqueológicos a exponer, el isotipo y la ampliación del listado de informantes claves.

Pensar la planificación desde una mirada interdisciplinar representa una oportunidad para alejarse de posturas cuasi-doctrinarias que no hacen más que encorsetar una disciplina tan fluida y compleja como es la comunicación. Pero olvidar por completo la producción de mensajes estratégicos es un riesgo que cualquier comunicador seguramente querrá evitar. En este caso particular, los integrantes de la localidad incorporaron sus puntos de vista, sus subjetividades y emociones en la planificación en forma indirecta durante la recolección de datos y también en forma directa por medio de sugerencias y al mencionar los aspectos en los que no estaban interesados. En esta instancia se avanzó en algunos puntos: el lugar de realización no debía estar en el centro de Cafayate, la muestra debía estar destinada a los cafayateños y vecinos de La Banda de Arriba y no a los turistas, qué objetos serían expuestos, el isotipo debía ser el felino grabado de una de las vasijas, entre otras cuestiones.

A partir de este planteo teórico y estratégico se empezó a trabajar en el desarrollo del plan de comunicación con la decisión de realizar un trabajo interdisciplinar que comprenda profesionales y estudiantes del área de la Comunicación y la Arqueología. La tarea de este equipo fue la de realizar el mapeo de actores en tareas como identificar, contactar y entrevistar a los informantes claves. El objetivo de esta tarea de intervención se centraba en reconstruir los hallazgos arqueológicos a partir de sus relatos y lograr la participación de estos actores en la confección del guion de la muestra.

El acercamiento inicial a la localidad se realizó desde una metodología cualitativa en tanto paradigma que involucra prácticas materiales e interpretativas con las que se pretende hacer visible el mundo y transformarlo (Vieytes, 2004). Desde este marco, se otorgó importancia a un escenario natural para el desarrollo de la investigación, en este caso, la localidad de Cafayate. Así se indagaron los significados que los distintos actores le otorgan a los bienes arqueológicos que allí se encuentran. Se operó a partir de la interpretación de los sucesos, situaciones y acciones de los propios involucrados. 
El hallazgo por parte de unos niños de una tumba en el año 2006 no sólo dio lugar al relato de la situación y de los objetos arqueológicos rescatados, sino a la experiencia de cada uno de los integrantes de la familia ante la presencia de arqueólogos, autoridades, policía y medios de comunicación en La Banda de Arriba (Figura 1).

Brevemente, los objetivos del plan comunicacional fueron promocionar la muestra con el público objetivo, generando interés y logrando que los públicos objetivos valoricen los bienes arqueológicos de la localidad. Las estrategias diseñadas consistieron en utilizar medios de comunicación tradicionales locales para difundir la actividad, explotar los medios digitales (redes sociales), generar contacto directo y participativo con los públicos objetivos. Finalmente, las acciones propuestas fueron la realización de entrevistas etnográficas con los públicos objetivos (informantes claves), diseño de isologotipo y su aplicación en soportes visuales y audiovisuales (recuperando la mirada de los públicos objetivos), acciones de prensa concreta con medios locales (partes de prensa, cortos audiovisuales), búsqueda de auspiciantes locales, desarrollo de redes sociales (Facebook y YouTube), elección del salón y videos comunicacionales a exponer en la inauguración y en las redes.

\section{Relevamiento de información para el diseño de la exposición y del plan comunicacional}

El relevamiento para el diseño de la exposición y del plan comunicacional se basó en un trabajo etnográfico con los actores estratégicos identificados previamente. En una primera fase, desde un punto de vista instrumental y para las tareas iniciales con la localidad, se utilizaron las entrevistas individuales mediante la confección previa de agendas conversacionales que contenían temas para guiar la conversación hacia los objetivos propuestos (reconstruir la historia de los hallazgos arqueológicos, por ejemplo). Los datos de ubicación de los informantes claves fueron proporcionados por los arqueólogos que participaron en los rescates arqueológicos y luego se fueron sumando informantes a medida que se realizaban las entrevistas. Las agendas fueron realizadas por los estudiantes bajo la orientación de los docentes y resultaron fundamentales para generar temas consensuados y orientativos para todos los equipos de entrevistas (Figura 2). Los ejes fueron: la posibilidad de la exposición arqueológica, los interrogantes, el lugar, los alcances de la misma y qué se debería relatar en la muestra. En estos casos se utilizó la observación no participante y charlas informales registradas en un cuaderno de campo. En esta instancia no se emplearon recursos audiovisuales y se consultó a los vecinos de la Banda de Arriba para participar posteriormente en entrevistas comunicacionales (lugar, entrevistados, horarios, etcétera).

Desde la perspectiva comunicacional, las entrevistas etnográficas son empleadas con una metodología similar a la implementada en la Antropología, diferenciándose de la entrevista periodística, que intenta seducir a un público receptor, en este caso se intenta incluir al público objetivo y no seducirlo. En estas entrevistas se utilizan agendas conversacionales y no preguntas guías como en el periodismo, donde los desarrollos de las mismas no están sometidas a un tiempo acotado, sino que se realizan hasta que el tema es finalizado por el entrevistado.

En una segunda fase, la documentación se apoyó en el registro audiovisual, utilizando las siguientes técnicas: testimonio de vida, recupero de la memoria, identificación de futuribles (visión prospectiva), análisis colectivo de los problemas denotados por los participantes desde una postura multidimensional. Cabe aclarar que el proceso de la descripción de los dichos de los participantes no es exclusivamente la obtención y la acumulación de datos y su tabulación correspondiente, sino que se relaciona con las prácticas observadas y por haber adoptado una perspectiva etnográfica aportan a una comprensión profunda del fenómeno (Figura 3). 


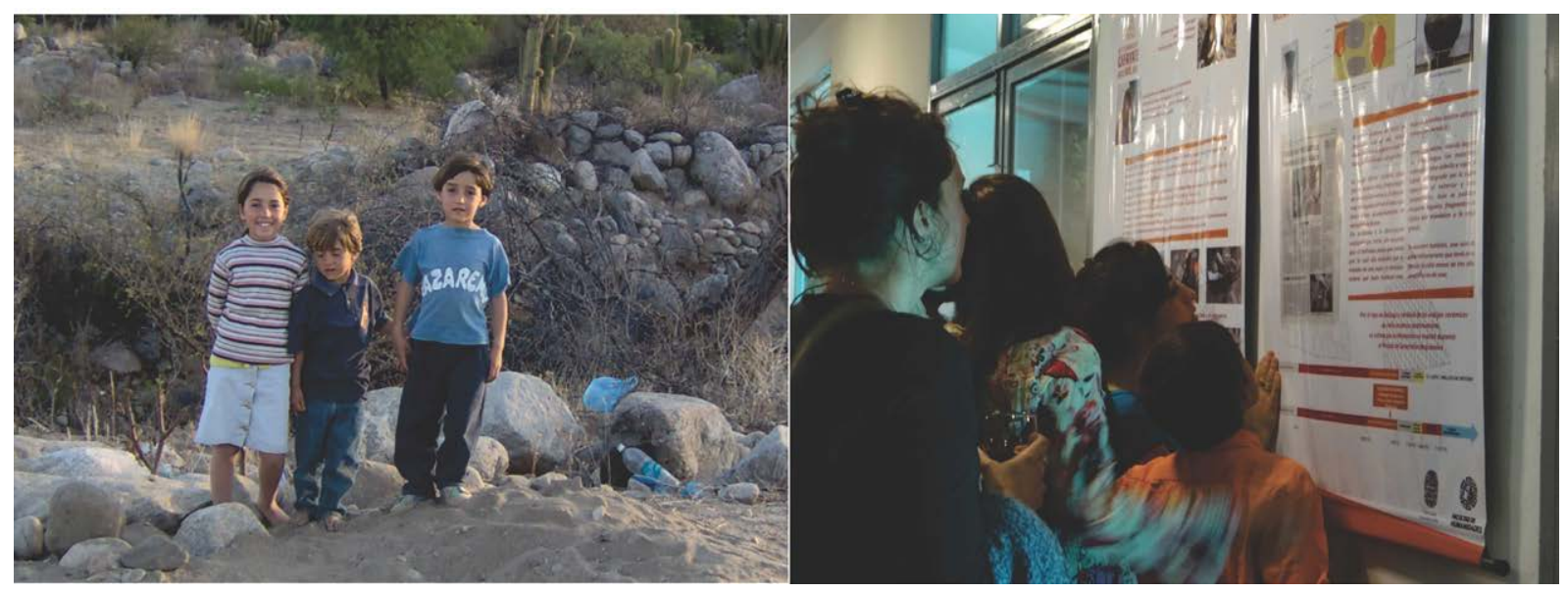

Figura 1. Los hermanos Gyurkovics durante el rescate del año 2006 (a) y Su Gyurkovics durante la inauguración de la muestra en 2014

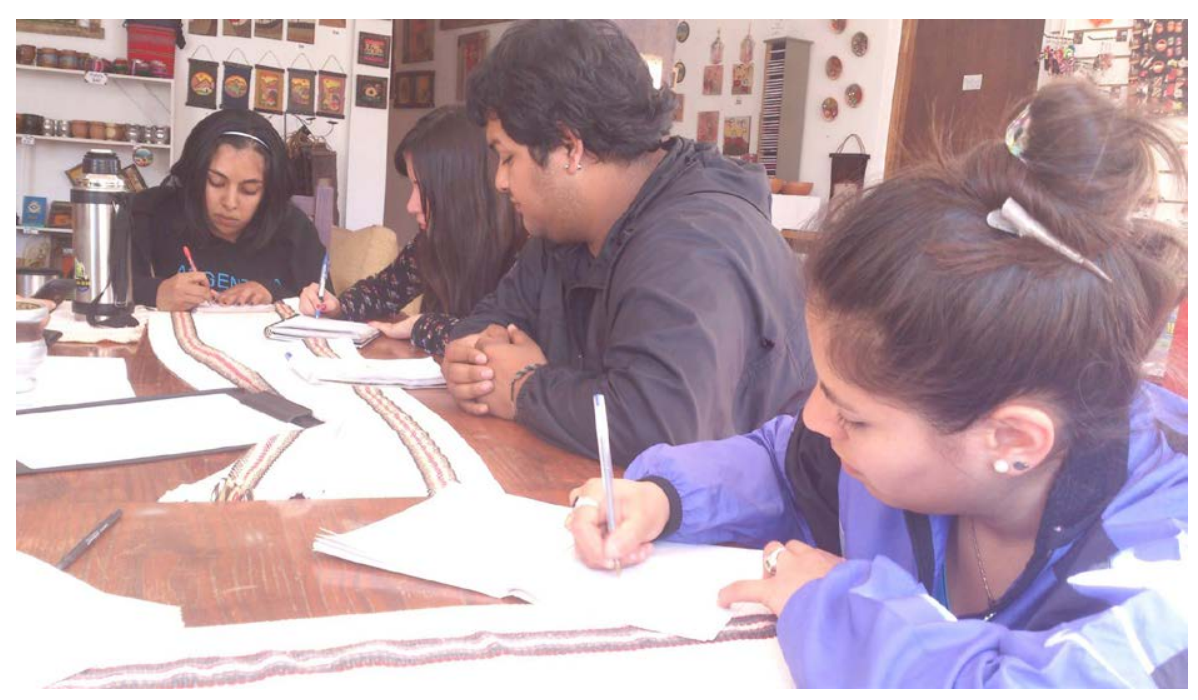

Figura 2. Confección previa de agendas conversacionales consensuadas por los estudiantes de Ciencias de la Comunicación y Arqueología.

A partir de los datos relevados se logró llegar a un momento inicial óptimo del plan de comunicación ya que se contó con la opinión de los participantes. A partir de este cimiento informacional se definieron los temas de la muestra, el isologotipo y su tipografía, las piezas a exponer, sus elementos identitarios, el alcance, el lugar, los soportes de comunicación necesarios para difundir su lanzamiento y otros parámetros necesarios para la planificación.

Respecto al isologotipo, se aisló el motivo de un felino con pipa acodada que se encuentra grabado en una vasija globular negro pulida del sitio la Banda de Arriba 1. Si bien se contaba con varias opciones, entre los relatos de los vecinos se destacaba el recuerdo de la "olla del gatito" y la de los "pajaritos", pero por la simpleza y características del diseño y la imagen se optó por el felino. Posteriormente se pudo observar la incorporación del felino en producciones artesanales locales. El felino formó parte de los banners y afiches de promoción, cartas de invitación, página de Facebook, canal de YouTube, apoyos museográficos, etcétera (Figura 4).

La realización de las entrevistas a los vecinos que participaron en diferentes instancias de las investigaciones arqueológicas se constituyó como el eje del proyecto de exposición. 


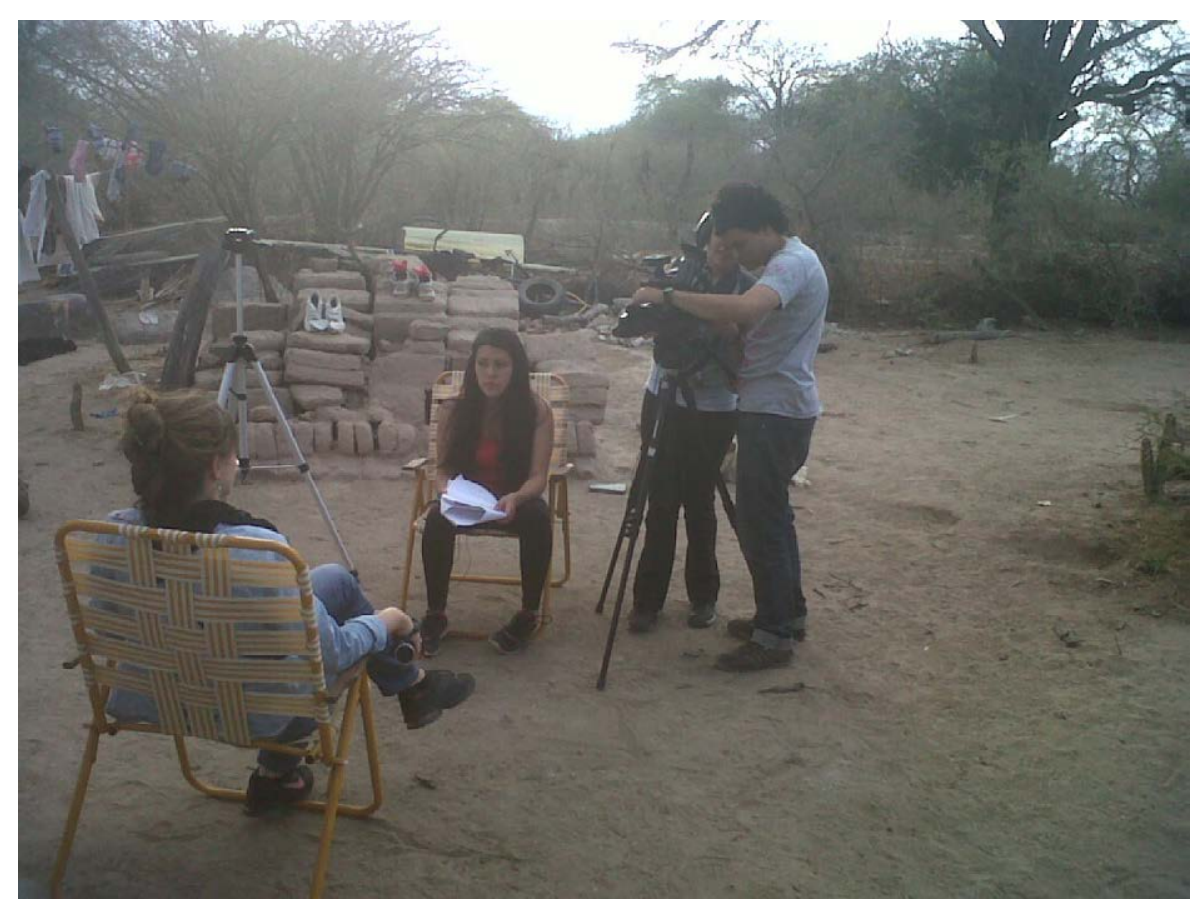

Figura 3. Entrevistas en la Banda de Arriba con registro audiovisual.

3. El pedido de un museo de gestión pública se realizó principalmente por la existencia del Museo Privado Rodolfo Bravo.

La intención fue desplazar la atención del objeto arqueológico al sujeto de la muestra y mostrar al "denunciante/descubridor" del hallazgo, a los colaboradores durante los rescates y a los vecinos, entre otros. Los entrevistados expresaron de manera recurrente su interés en conocer la ubicación de los hallazgos efectuados en cada uno de los lotes del paraje La Banda de Arriba, los motivos por los cuales los bienes se encuentran en Salta y el pedido de la realización de un museo arqueológico de gestión pública ${ }^{3}$ en la misma ciudad de Cafayate.

Durante las entrevistas se pudo apreciar un recuerdo permanente de las campañas arqueológicas que habían sido realizadas en los años 1986, 1988, 1990, 2001 y 2006, con descripciones precisas de los bienes obtenidos en excavación. Se pudo apreciar que los objetos no sólo tenían la importancia testimonial del pasado de las poblaciones prehispánicas, sino que habían sido resignificados por los pobladores de la Banda de Arriba como referentes de la historia reciente, familiar e incluso personal. Por ejemplo, la vasija globular negra pulida con el grabado del felino con pipa acodada se destaca por sus características técnicas, como evidencia cronológica relativa del período Formativo, su participación en el pasado de rituales (complejo del cebil) e inclusión en los circuitos de interacción puneños; pero los entrevistados hacen referencia al momento de hallazgo, las historias familiares, las actividades laborales que estaban desarrollando en ese momento, las circunstancias de la comunicación a la dueña de la finca donde trabajaban (y su colaboración), la relación con las autoridades del Museo de Antropología y las anécdotas con las arqueólogas por mencionar algunas, pero enmarcadas en la conformación del paraje (loteo, construcción de las viviendas, caminos y servicios). Así, posteriormente los textos ubicados en los apoyos museográficos eran encabezados con las fotografías y frases de los entrevistados (Figura 5). Para el grupo de arqueología ${ }^{4}$ con esta búsqueda etnográfica se pudo rescatar información que no había sido registrada en los informes y publicaciones arqueológicas.

\section{El diseño de la exposición como espacio de negociación}

En esta exposición temporaria la finalidad primera no era hacer visible la obra del artista ni el objeto arqueológico, sino la comunicación con la comunidad, más precisamente 


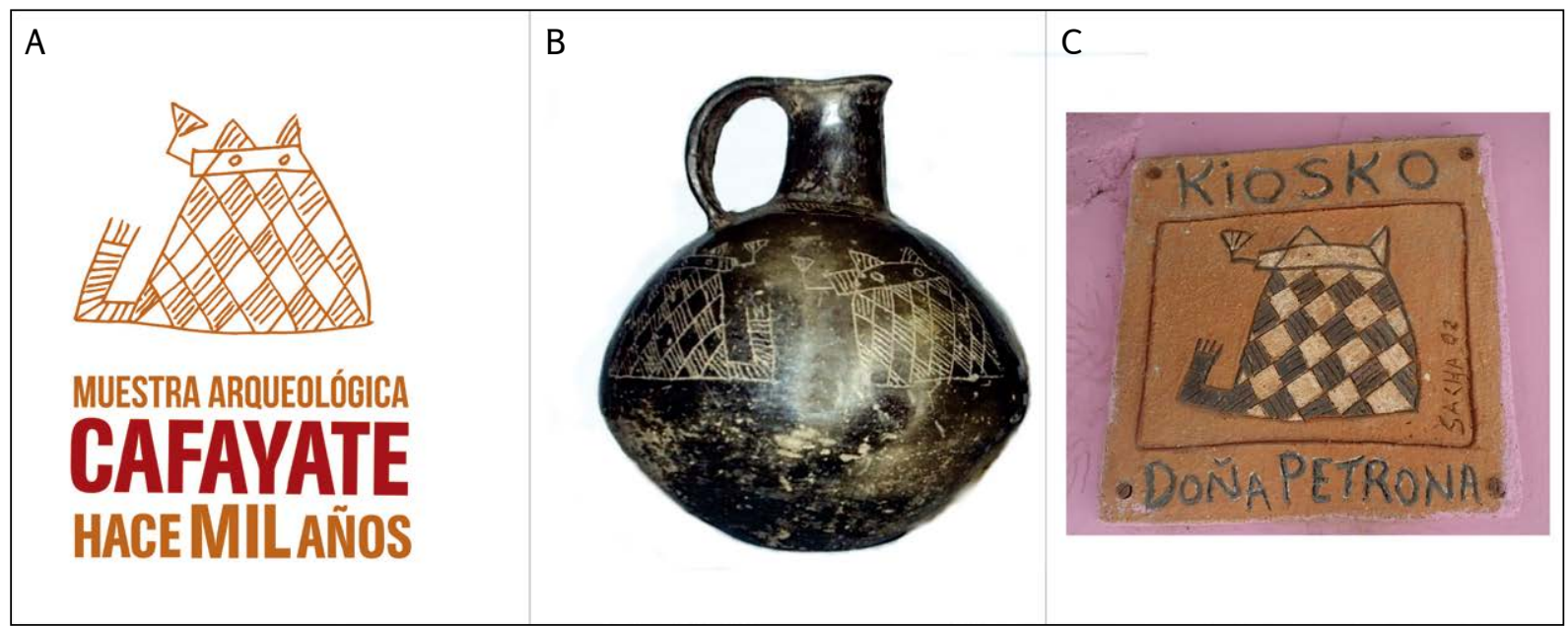

Figura 4. A) isologotipo de la muestra arqueológica "Cafayate hace mil años", B) vasija de la Banda de Arriba 1, C) cartel en un local comercial de la Banda de Arriba.

con los vecinos del paraje de la Banda de Arriba. Si bien se siguieron los lineamientos básicos de la museografía, las adecuaciones se realizaron a partir de la negociación con la localidad y las autoridades municipales y provinciales, los resultados de las investigaciones arqueológicas, los bienes arqueológicos, el espacio y la conservación. El diseño de la exposición temporal comprende el diseño y planificación, definición del espacio (estudio y organización), gestión y producción, materiales y fabricación (paneles, vitrinas, bases), iluminación, información, señalética, embalaje y traslado de bienes arqueológicos, instalación y montaje, seguridad y protección. En síntesis, el empleo de cada técnica debió ajustarse a la negociación y a la disponibilidad de los recursos materiales y humanos en Cafayate (Alonso y García, 1999; Maure, 1995; Perales Piqueres, 2005, 2006; Ramírez Celis, 2012).

La exposición diseñada fue de tipo temporal, con una duración de quince días y a la vez itinerante porque se previó trasladar la muestra desde Cafayate al Museo de Antropología de Salta ${ }^{5}$. Por lo cual fue necesario efectuar ajustes a la selección de los bienes arqueológicos, la cartelería y adaptar los recursos mobiliarios (vitrinas) y el espacio del salón de usos múltiples (SUM) de Cafayate.

En referencia al contenedor de la exposición, se eligió al SUM de la plaza Michel Torino de la ciudad de Cafayate que está ubicado en un punto geográfico intermedio entre el centro de la ciudad y el paraje La Banda de Arriba, es un lugar de encuentro y recreación recientemente inaugurado y por sus características arquitectónicas resultaba muy adaptable para el montaje de la exposición.

Los cuidados vinculados a la temperatura y humedad fueron salvados por el clima seco y templado de la región que es ideal para la conservación de los materiales. La orientación del edificio impide el ingreso de luz natural en forma directa y hace propicia la exhibición en horarios diurnos sin que las piezas arqueológicas sean afectadas. Por razones presupuestarias, se decidió un horario de atención al público matutino y vespertino para evitar la instalación de luces adicionales en la exposición y se descartaron los horarios nocturnos. No fue necesario instalar sistemas correctivos para la humedad, salidas de aire, muros o pisos ya que el edificio se encuentra en perfectas condiciones. Otro aspecto fundamental en la elección del salón fue la presencia de un destacamento policial en forma permanente en la misma plaza y colindante con la sala de exposición.
5. Al momento de trasladar la exposición a Salta, en el Museo de Antropología J. M. Leguizamón se iniciaron tareas de refacción y el material fue trasladado al depósito. 


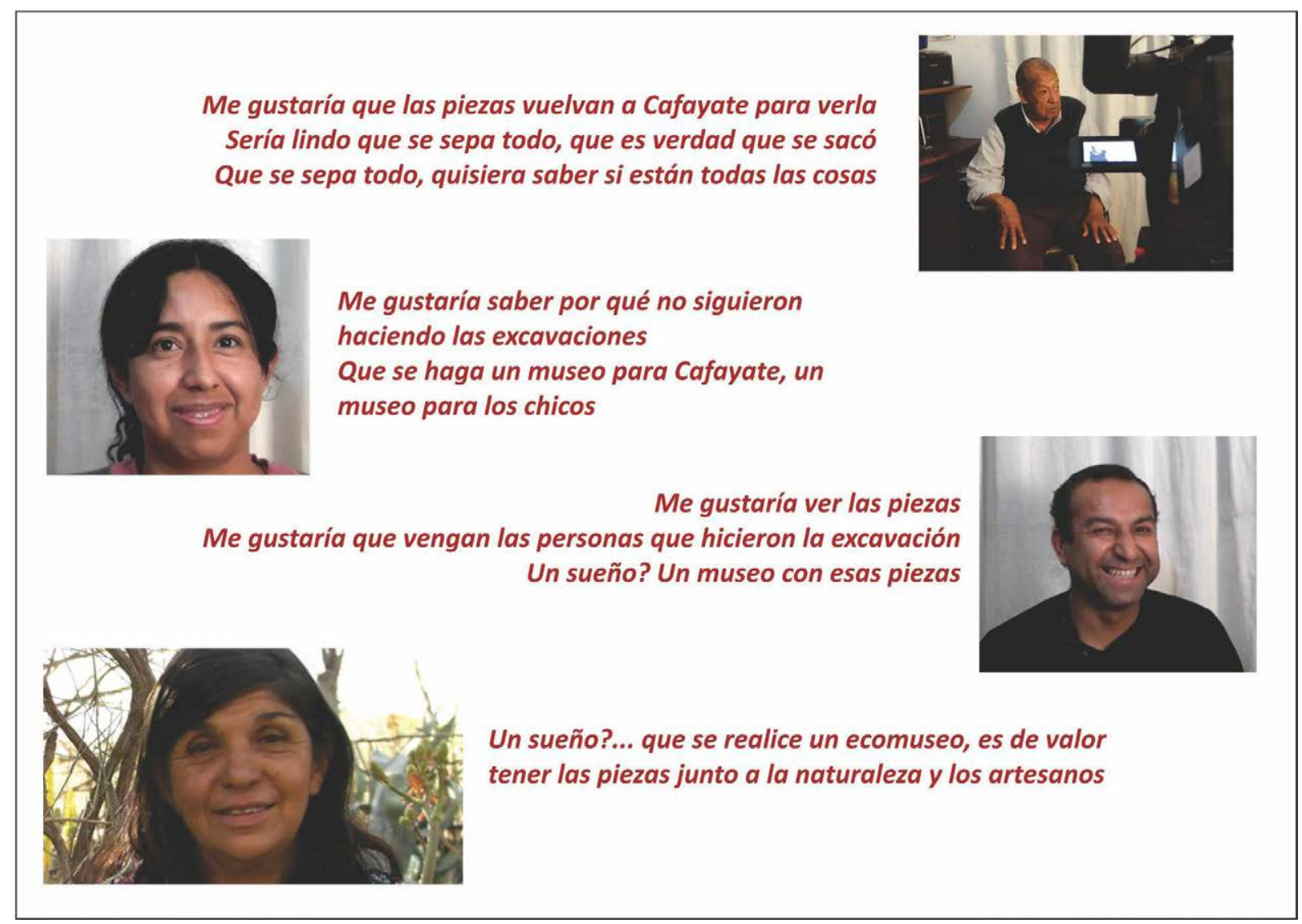

Figura 5. Detalle de uno de los apoyos museográficos de la muestra "Cafayate hace mil años", donde se pueden observar algunas de las frases mencionadas por los vecinos de la Banda de Arriba.

El salón fue utilizado como un espacio abierto y libre de divisiones donde conviven las vitrinas con los bienes arqueológicos, las instalaciones y la cartelería. Si bien las vitrinas y la cartelería fueron organizadas de manera temática (por sitio y hallazgos arqueológicos), el recorrido era libre lo que permitió a los visitantes desplazarse en forma independiente. A los fines de organizar el ingreso, fundamentalmente con las delegaciones de estudiantes, se habilitaron puertas de ingreso y salida.

Una vez decididos los colores y el diseño de la marca Muestra Cafayate, se adaptaron la gráfica de promoción y los videos de presentación y difusión. El uso de colores fue un tema central al momento de diseñar la exposición para conjugar el color blanco neutral de las paredes del salón (que no podía ser modificado) con las vitrinas, las bases de los objetos, los objetos, los apoyos museográficos internos y externos al salón.

Los apoyos museográficos internos se diseñaron y ubicaron con neutralidad para no competir con las instalaciones y objetos ubicados en las vitrinas. Tanto el panel de presentación como los textos fueron organizados por sitio arqueológico y confeccionados en función de las preguntas e inquietudes planteadas por los vecinos de Cafayate. Se obviaron descripciones técnicas o científicas no vinculadas a las expectativas de la localidad. Los apoyos ubicados en las paredes contenían las inquietudes de los entrevistados y sus respuestas, así como también gráficos, fotos y esquemas que remitían a la observación en las vitrinas. Para la confección de los apoyos museográficos se siguieron los temas expresados por los vecinos de la Banda de Arriba y el análisis de las problemáticas definidas en las entrevistas. Estos temas incluyeron: ubicación actual de los hallazgos de la Banda de Arriba 1 y los motivos por los que fueron trasladados 
al Museo de Antropología de Salta, descripción de los lugares donde se encontraron las tumbas, cantidad de tumbas, sexo y edad de los restos óseos humanos, antigüedad de los entierros, incorporación de una línea de tiempo con la ubicación temporal del sitio más antiguo de la Banda de Arriba, descripción de los objetos de cerámica que formaban parte del acompañamiento funerario de las tumbas, funciones de las vasijas, los análisis realizados y su interpretación, relato del hallazgo realizado por la familia Gyurkovics en la Banda de Arriba 5, explicación de la restauración y conservación realizado a las vasijas, relato de los hallazgos de la Banda de Arriba 6. Finalmente, un listado de los investigadores, estudiantes, vecinos, empleados municipales y autoridades que participaron en todas las excavaciones, colaboradores para la muestra, auspiciantes, equipos de investigación, extensión y restauración.

El apoyo financiero se realizó por parte de la UNSa y otras instituciones se comprometieron con acciones específicas sin el aporte de recursos financieros directos. La Municipalidad de Cafayate y el Museo de Antropología realizaron gestiones, difusión local, contratación de equipos de sonido/proyección y traslados de materiales que son los de mayor dificultad para ser realizados por el equipo de investigación. Las tareas de restauración y conservación de los objetos a exponer fueron aportadas por el Taller de Conservación y Restauración de la Dirección General de Patrimonio Cultural de la Provincia de Salta (Figura 6). Las guías en la exposición fueron realizadas por personal de la Dirección de Cultura de Cafayate que habían participado en los cursos de capacitación implementados en años anteriores. También se contó con la participación de empresas particulares del medio que colaboraron en productos y servicios. El compromiso y negociación entre las instituciones hizo posible que el montaje se realice sin contratiempos en las fechas previstas (Figura 7).

\section{La muestra arqueológica “Cafayate hace mil años” en acción}

El título de la muestra responde a una de las inquietudes planteadas por los vecinos, la antigüedad de los hallazgos en Cafayate. No resultaba un tema menor ya que la ciudad fue organizada en el siglo XX y no tiene fecha de fundación como los pueblos vecinos.

Uno de los aspectos de cuidado fue el acto de inauguración, donde el propósito propuesto por el equipo organizacional era acercar a los entrevistados y que formen parte de la exposición como protagonistas. Para ello los estudiantes de comunicación realizaron dos videos: el primero fue de tipo documental con los antecedentes de las investigaciones arqueológicas, mientras que el segundo se basó en los relatos locales sobre los hallazgos, las experiencias y el significado del pasado en la vida actual de los pobladores de Cafayate ${ }^{6}$, sin incluir contenido científico. Efectivamente, la proyección de los videos antes de habilitar el ingreso a la sala de exposiciones se realizó en un ámbito formal para convertirse en un espacio de identificación y encuentro entre la organización y los públicos objetivos (Figuras 8 y 9).

Como resultados concretos de la implementación de la planificación comunicacional y de la exposición se pueden enumerar los siguientes logros: montar la muestra en la fecha prevista durante quince días en Cafayate, confeccionar un guion expositivo que brindó respuestas a las inquietudes de los actores sociales, consensuar criterios de trabajo interdisciplinar (arqueología, conservación y comunicación), contar con más de 1400 visitantes (95\% cafayateños) (Figura 10). El Facebook de la muestra logro reunir más de 1000 visitas en la primera semana de su lanzamiento y el Canal de YouTube superó las 1000 reproducciones de los videos de promoción durante el primer mes de difusión. Finalmente, el equipo pudo comprobar que las acciones trans-mediáticas, y en particular en las redes sociales, pueden ser utilizadas eficientemente en conjunto a otras acciones clásicas para promover el lanzamiento de un evento social e incentivar el involucramiento de la localidad.
6. Los videos se encuentran disponibles en el canal de YouTube de la Muestra Cafayate, a través de los siguientes URL: https://www. youtube.com/watch?v=d_gTanyxRDc, https://www.youtube. com/watch?v=bFlkrBhg4fs y https://www.youtube.com/ watch?v=g3jn1dqAvcA. 


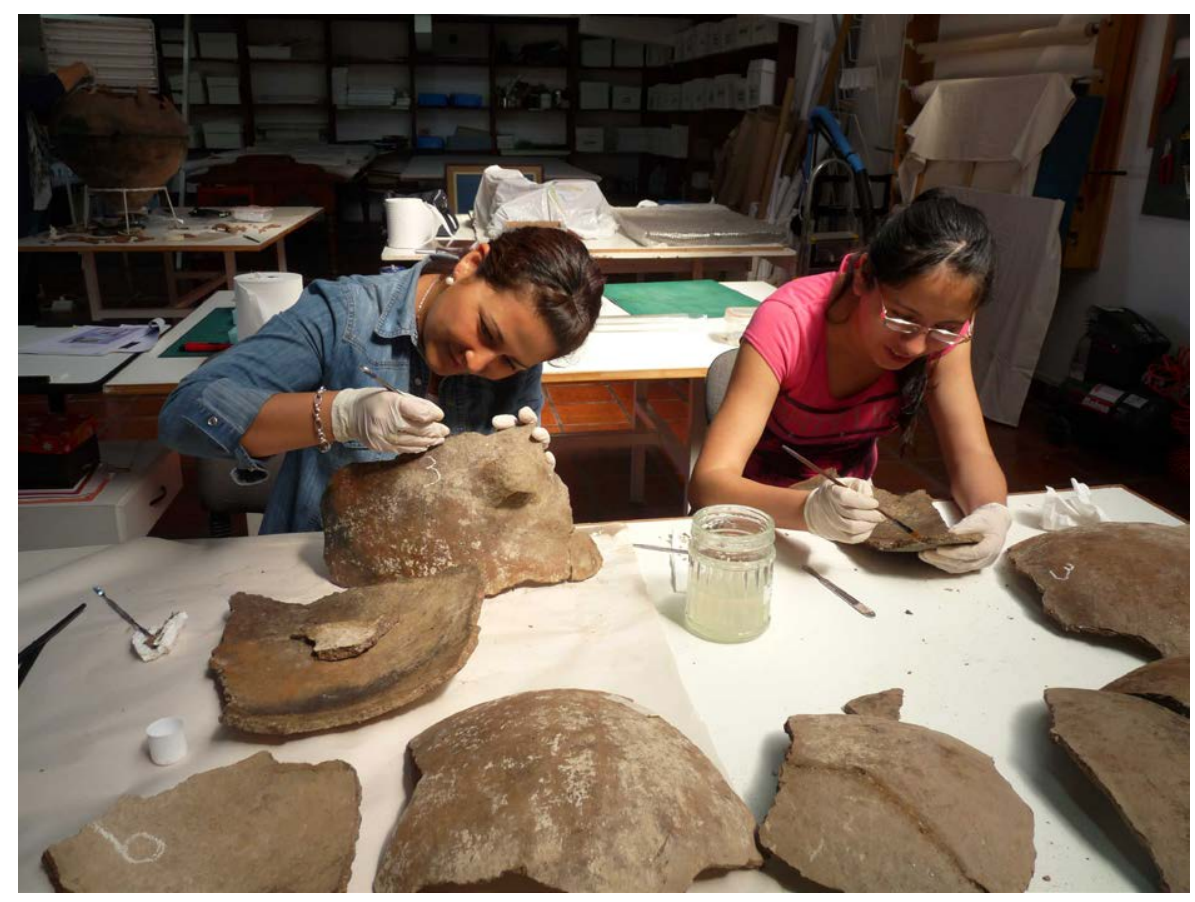

Figura 6. Tareas de restauración de las vasijas arqueológicas a ser expuestas y provenientes de La Banda de Arriba (Departamento de Restauración y Conservación de la Dirección General de Patrimonio Cultural de la Provincia de Salta).

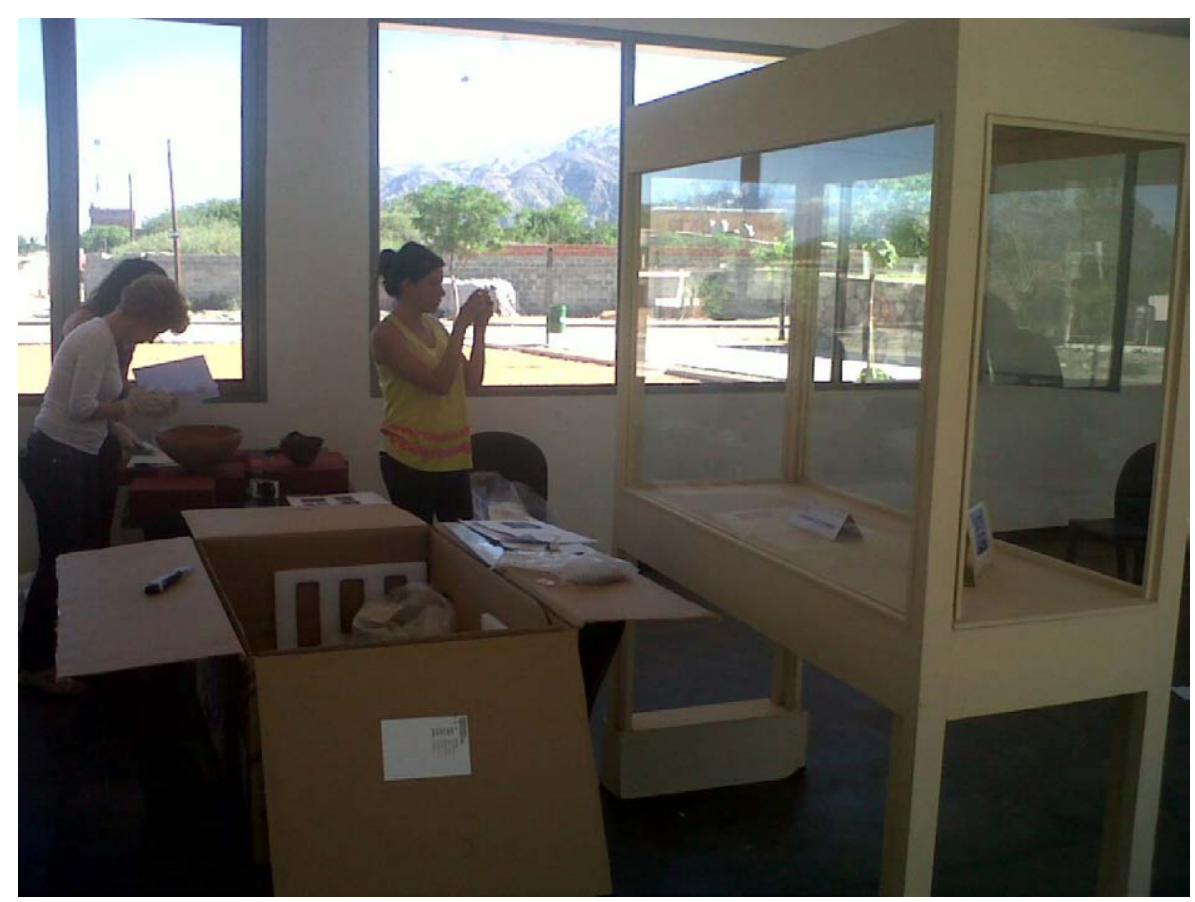

Figura 7. Montaje de la muestra arqueológica “Cafayate hace mil años”.

Finalmente, durante el acto inaugural las autoridades municipales se hicieron eco de la necesidad de contar con un museo de arqueología de gestión estatal en Cafayate. Si bien se puede considerar una respuesta de tipo política, hasta el momento no se había generado la necesidad del producto museo arqueológico en Cafayate por parte de la localidad y el pedido concreto a las autoridades. 


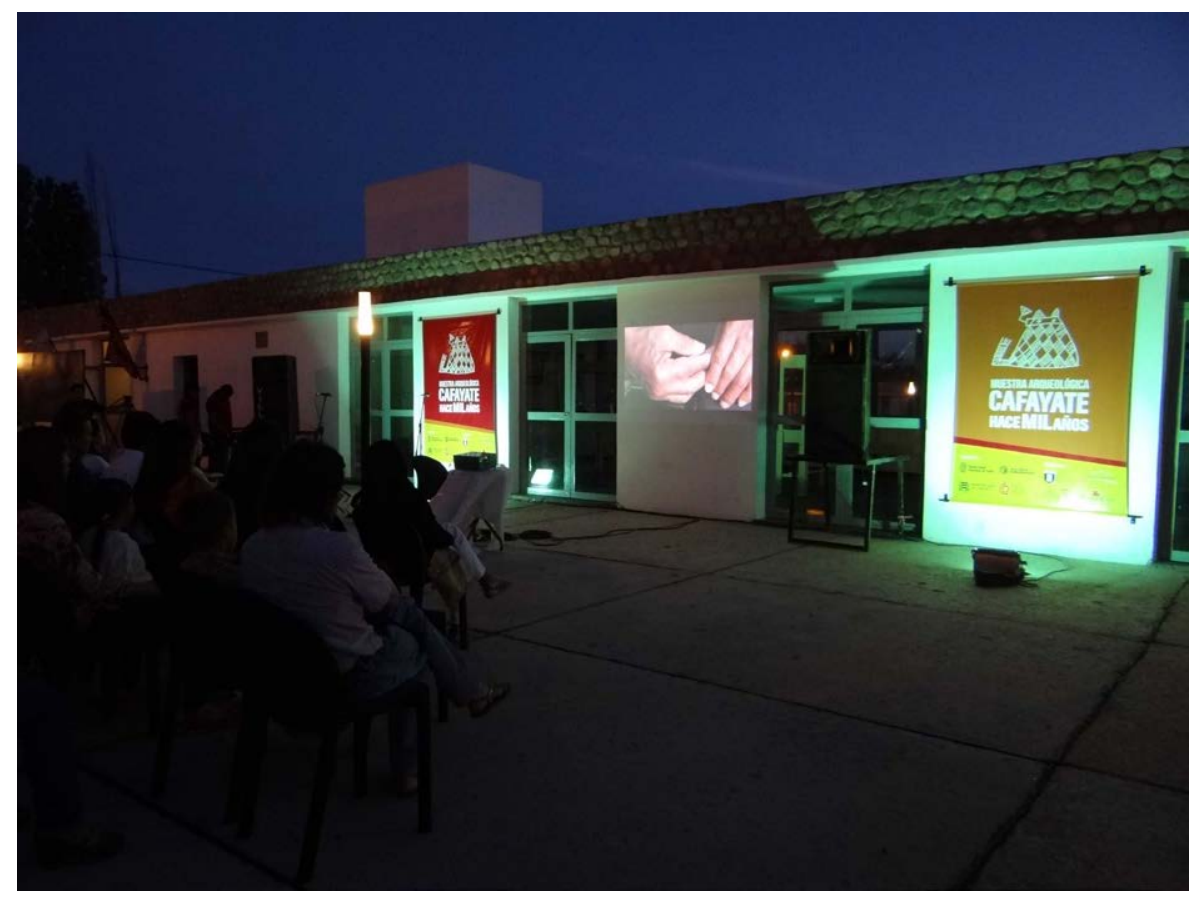

Figura 8. Vista externa del salón con la proyección del documental durante la inauguración (sector externo del salón).

\section{Reflexiones y nuevas líneas de trabajo}

Las actividades de extensión y divulgación de la producción científica suelen tener una iniciativa académica originada en diversos intereses, proveniente de las instituciones de investigación o universitarias donde el discurso dominante es el del científico que determina qué es lo que la localidad debería conocer o puede comprender sobre el pasado de los pueblos originarios. Elaborar una exposición con un guión museológico basado en las inquietudes, cuestionamientos e iniciativas de los vecinos de Cafayate fue el mayor desafío profesional al que nos enfrentamos porque no se sabía si la exposición sería un éxito o un fracaso, aspecto que no dependía directamente de los recursos museográficos sino de la identificación de los vecinos de la Banda de Arriba con la propuesta.

Con anterioridad, el equipo ya había desarrollado actividades de extensión y voluntariado universitario en Cafayate con el acompañamiento de educadores bajo la premisa de realizar una consulta previa pero no se observaba una apropiación del pasado: era la historia de otros. Con esta muestra, el objetivo general consistió en gestar nuevas acciones de comunicación que les permitiesen a los arqueólogos vincularse con los públicos objetivos.

Son dos los aspectos que se deben considerar al momento de reflexionar sobre la exposición realizada. El primero es metodológico, vinculado a las acciones de comunicación estratégicas implementadas para este proyecto. El segundo es a largo plazo y se halla vinculado a la divulgación de la producción científica de los resultados a la localidad de Cafayate en general y a La Banda de Arriba en particular.

Más allá de las técnicas utilizadas para relevar información y de las estrategias desplegadas para alcanzar los objetivos específicos propuestos, es necesario recaer en la idea de que todos los datos que se obtienen y las acciones que se realizan están cargados de teoría. Y también es imprescindible insistir en la idea de que la planificación 


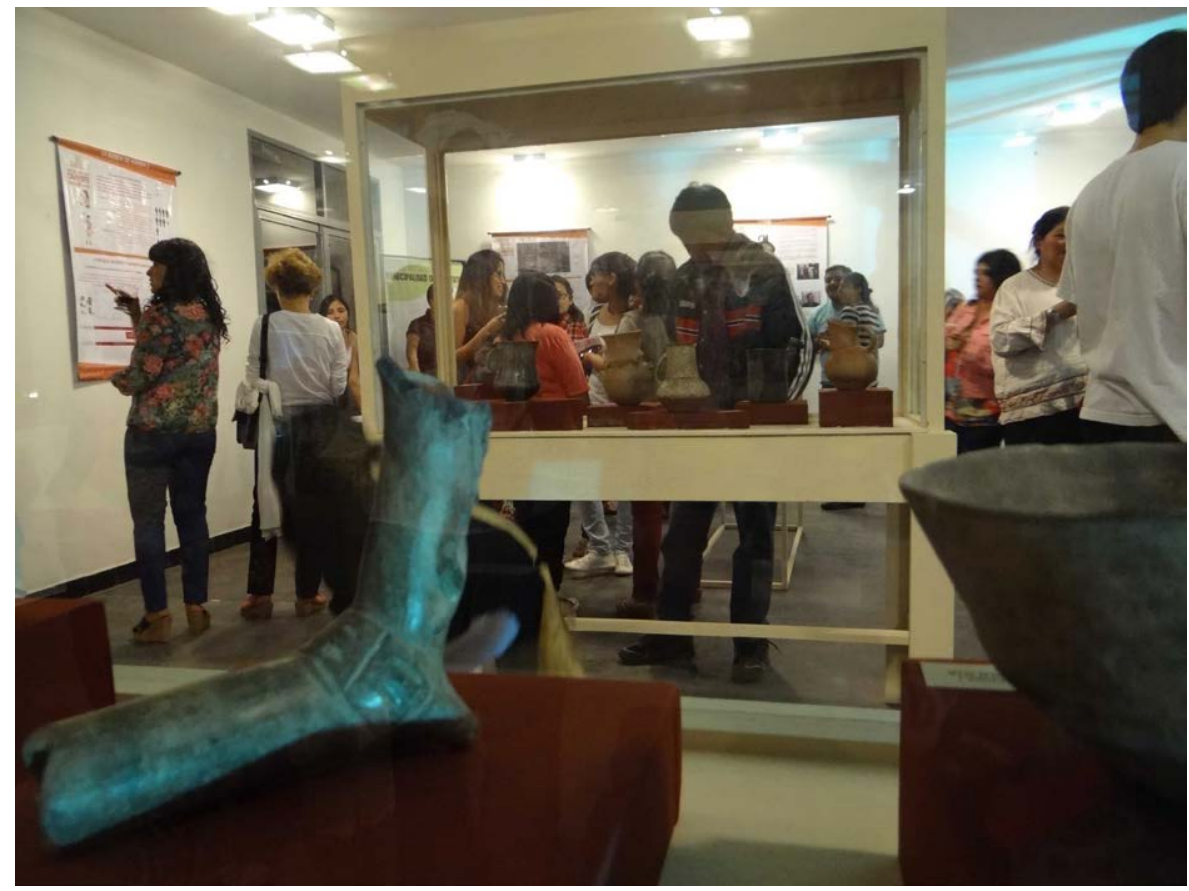

Figura 9. Inauguración de la muestra con la participación de los vecinos de la Banda de Arriba, investigadores, montajistas y autoridades municipales.

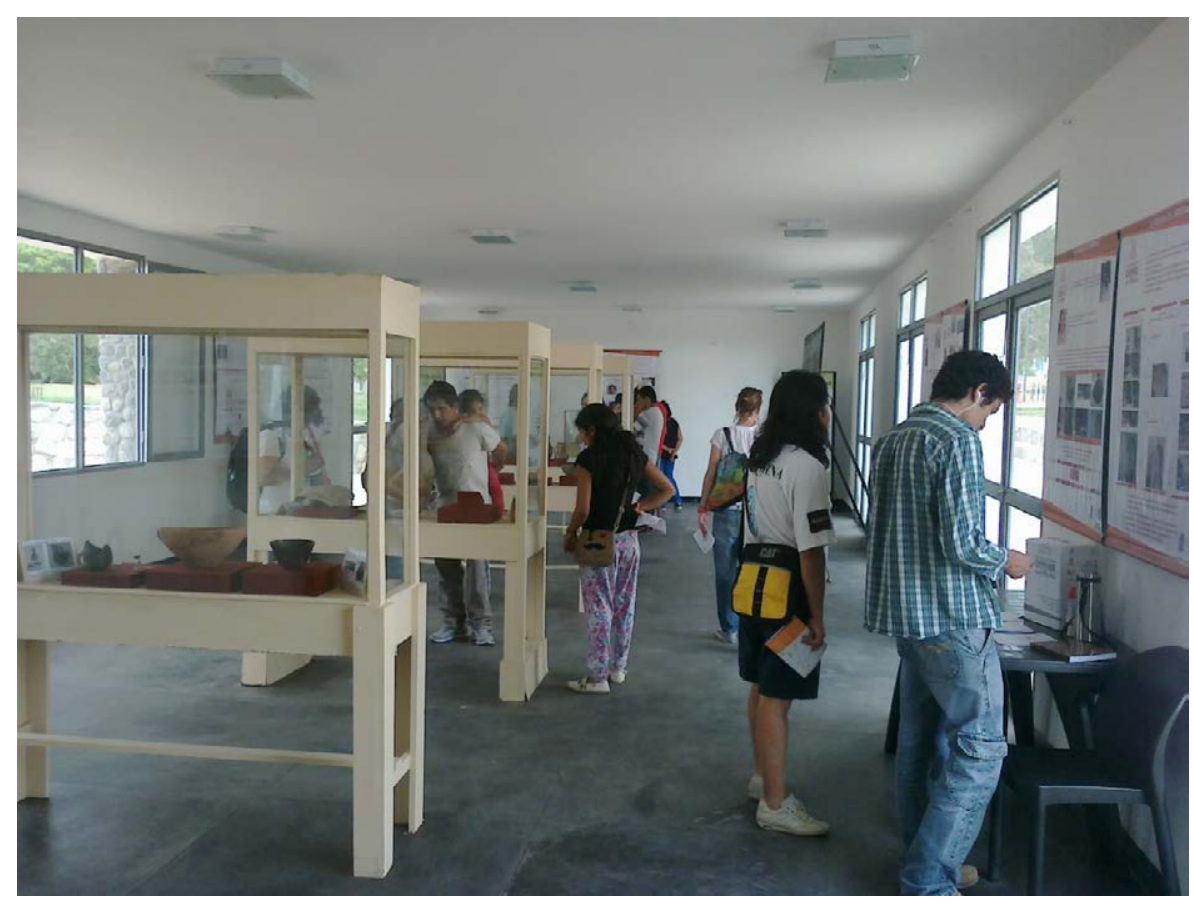

Figura 10. La muestra contó con una fluida asistencia, siendo el 95\% de los visitantes de la localidad de Cafayate. 
encierra en sí misma acciones de gestión, diagnóstico y de seguimiento que se entrelazan constantemente, enmarcando un espacio en donde conviven la teoría y la acción, a partir de los cuales las decisiones tomadas no son improvisadas y menos fijas, porque intentan inevitablemente adaptarse al entorno social en el que son desplegadas. El caso de la muestra en Cafayate puede servir para ejemplificar lo mencionado anteriormente: las recetas no existen porque los diversos entornos sociales suelen destruirlas. Sin embargo, la idea de que la planificación y la comunicación pueden tener miradas interdisciplinarias es el camino más recomendable para trabajar en esta área, sin proponer recetas para comenzar acciones de divulgación.

En segundo lugar, la divulgación de la producción científica arqueológica a la localidad no puede ser considerada como unilateral, dado que en todo proceso de comunicación es esperable una respuesta. Si se trata de promover a largo plazo la conservación de los bienes arqueológicos es necesario propiciar un proceso de apropiación de ese pasado arqueológico, no como un pasado lejano y de los pueblos originarios, sino como un pasado reciente del que se pueda formar parte. En el caso de la muestra, los vecinos de La Banda de Arriba hicieron propio el pasado remoto y lo resignificaron a partir su historia personal, familiar y local.

La evaluación de la muestra puede ser cuantitativa si se considera el número de visitantes, pero lo que interesaba aquí era lograr una la legitimación de las investigaciones por parte de los vecinos de La Banda de Arriba en particular y de Cafayate en general. De forma concreta y al cerrar la muestra, el equipo del proyecto Cafayate fue solicitado por parte de los pueblos originarios, particulares y autoridades municipales para participar en prospecciones en sectores con sitios arqueológicos. No se puede decir que se abrieron en forma permanente las puertas a la investigación arqueológica sino que se establecieron nuevas maneras de entablar el diálogo con la localidad de Cafayate.

\section{Agradecimientos}

Este proyecto fue realizado con el subsidio otorgado por la Secretaría de Extensión Universitaria de la UNSa y con ayuda económica de la Facultad de Humanidades (UNSa). Nuestro agradecimiento a los vecinos de La Banda de Arriba (Cafayate), a las autoridades de la Municipalidad de Cafayate y de la Dirección General de Conservación del Patrimonio de la Provincia de Salta (Museo de Antropología de Salta y Taller de Conservación y Restauración) y a las autoridades y personal de Apoyo Universitario de la Facultad de Humanidades (UNSa). La muestra contó con la colaboración de Hotel Asturias, Hotel Los Sauces, Sindicato de Pasteleros de Salta y Bodegas Nanni. Los resultados de la investigación básica arqueológica de la Banda de Arriba ya fueron publicados oportunamente, pero este artículo se realiza a instancias de colegas que sugirieron que dar a conocer esta experiencia puede aportar a la discusión de una problemática actual: transferir el trabajo arqueológico a la comunidad. Los autores agradecen las sugerencias de los evaluadores que han permitido mejorar la comunicación de esta experiencia teórica y metodológica. 


\section{Referencias citadas}

" Abatedaga, N. (2008). Comunicación epistemologías y metodologías para planificar por consensos. Córdoba: Editorial Brujas.

"Alonso Fernández, L. y García Fernández, I. (1999). Diseño de exposiciones. Concepto, instalación, montaje. Madrid: Alianza Forma.

» Bongiovanni, M. (2011). Los públicos en el proceso de comunicación pública. En A. Amado Suárez (Ed.), Auditoría de comunicación (pp. 49-60). Buenos Aires: La Crujía.

» Bonilla, J., Cataño, M., Rincón, O. y Zuluaga, J. (2012). De las audiencias contemplativas a los productores conectados. Cali: Sello Editorial Javeriano.

» Brunas, A., Ledesma, R.y Rivas, A. (2012). Informe final del taller Relaciones entre enseñanza, investigación y extensión. Trabajo presentado en las Primeras Jornadas Nacionales de Políticas de Investigación de las Facultades de Humanidades y Educación. Santa Fe, Argentina.

»Consejo Nacional de Investigaciones Científicas y Técnicas (CONICET), Dirección de Vinculación tecnológica, red de vinculadores (2016). Normativas y procedimientos. https://drive.google.com/file/d/oB6Xx7yuxx83XNE9SeDRfaG5MSko/view (Acceso: 22 de julio de 2017).

"Cruz, N. (2016). La planificación estratégica de la comunicación como dispositivo de mediación entre actores (organizaciones) para la solución de problemas sociales. Caso: Muestra Arqueológica Cafayate hace mil años. Salta-Cafayate año 2014. Trabajo presentado en la V Jornada de Investigación y docencia universitaria. México, D.F., México.

»Ledesma, R. (2010a). Valles de historia. Aportes a la educación patrimonial. Salta: Editorial Universidad Nacional de Salta.

»Ledesma, R. (2010b). El arte rupestre en el Sur del Valle Calchaquí (Salta, Argentina). Estudio de territorialidad por medio de marcadores gráficos. (Tesis Doctoral inédita). Universidad de Alcalá, España. https://www.educacion.gob.es/teseo/mostrarRef.do?ref=871518 (Acceso 22 de julio de 2017).

"Ledesma, R. (2014). La conservación del patrimonio. Relación entre investigación, docencia y extensión en la localidad de Cafayate (Salta, Argentina). Etnicex, 6, 71-83.

"Ledesma, R. y Subelza, C. (2009). Alcances y limitaciones para caracterizar las ocupaciones formativas en Cafayate (Salta). En M. C. Rivolta y R. Ledesma (Comp.), Las sociedades formativas en el NOA. Aportes discusión y replanteo (pp. 75-108). Salta: Instituto de Investigaciones en Ciencias Sociales y Humanidades (ICSOH), Facultad de Humanidades, Universidad Nacional de Salta, Grupo Editorial CEPIHA.

»Ledesma, R. y Subelza, C. (2014). Arqueología de Cafayate. Un enfoque desde su cerámica y arte rupestre. Salta: Editorial Universidad Nacional de Salta.

» Lo Celso, M., Lescano, B. y Barbarán, E. (200o). El impacto del Período Formativo en la zona sur del valle Calchaquí: La Banda de Arriba (Cafayate). Informe Final Proyecto № 702. Consejo de Investigación Universidad Nacional de Salta. Manuscrito inédito.

" Martin Barbero, J. (1987). De los medios a las mediaciones. México D.F.: G. Gill.

» Maure, M. (1995). La nouvelle muséologie, qu'est-ce que c'est?. En M. R. Shärer (Ed.), Museum and community II (pp. 127-132). Vevey: Alimentarium Food Museum. 
»Onocko Campos, R. (2007). La planificación en el laberinto. Un Viaje hermenéutico. Buenos Aires: Lugar Editorial.

»Perales Piqueres, R. (2005). La disyuntiva de las nuevas tecnologías en las exposiciones temporales. Museo: Revista de la Asociación Profesional de Museólogos de España, 10, 183-189.

»Perales Piqueres, R. (2006). Los museos locales y municipios en Extremadura. Creación y desarrollo. Museo: Revista de la Asociación Profesional de Museólogos de España, 11, 67-77.

» Prats, LI. (1997). Antropología y Patrimonio. Barcelona: Ariel Antropología.

» Prats, Ll. (2005). Concepto y gestión del patrimonio local. Cuadernos de Antropología Social, 10, 17-35.

» Ramírez Celis, L. F. (2012). Museografía: la exposición como espacio de negociación. En C. Muñoz Uribe (Ed.), Museología, Curaduría, Gestión y Museografía. Manual de producción y montaje para artes visuales (pp. 38-53). Bogotá: Ministerio de Cultura, República de Colombia.

»Subelza, C. (2008). Manejo de recursos para el proceso productivo de la cerámica Formativa en el sector meridional del valle Calchaquí y sus implicancias sociales. (Tesis de Licenciatura inédita), Universidad Nacional de Salta, Argentina.

»Vieytes, R. (2004). Metodología de la investigación en organizaciones, mercado y sociedad: epistemología y técnicas. Buenos Aires: Editorial de las Ciencias. 